\title{
Grey zones in the diagnosis of adult migraine without aura based on the International Classification of Headache Disorders-III beta: Exploring the covariates of possible migraine without aura
}

\author{
Aynur Ozge MD¹, Elif Aydinlar MD², Bahar Tasdelen PhD ${ }^{1}$
}

A Ozge, E Aydinlar, B Tasdelen. Grey zones in the diagnosis of adult migraine without aura based on the International Classification of Headache Disorders-III beta: Exploring the covariates of possible migraine without aura. Pain Res Manag 2015;20(1):e1-e7.

BACKGROUND: Exploring clinical characteristics and migraine covariates may be useful in the diagnosis of migraine without aura.

OBJECTIVE: To evaluate the diagnostic value of the International Classification of Headache Disorders (ICHD)-III beta-based diagnosis of migraine without aura; to explore the covariates of possible migraine without aura using an analysis of grey zones in this area; and, finally, to make suggestions for the final version of the ICHD-III.

METHODS: A total of 1365 patients (mean [ \pm SD] age 38.5 \pm 10.4 years, $82.8 \%$ female) diagnosed with migraine without aura according to the criteria of the ICHD-III beta were included in the present tertiary care-based retrospective study. Patients meeting all of the criteria of the ICHD-III beta were classified as having full migraine without aura, while those who did not meet one, two or $\geq 3$ of the diagnostic criteria were classified as zones I, II and III, respectively. The diagnostic value of the clinical characteristics and covariates of migraine were determined.

RESULTS: Full migraine without aura was evident in $25.7 \%$ of the migraineurs. A higher likelihood of zone I classification was shown for an attack lasting $4 \mathrm{~h}$ to $72 \mathrm{~h}(\mathrm{OR} 1.560 ; \mathrm{P}=0.002)$, with pulsating quality (OR 4.096; $\mathrm{P}<0.001)$, concomitant nausea/vomiting $(\mathrm{OR} 2.300 ; \mathrm{P}<0.001)$ and photophobia/phonophobia (OR 4.865; $\mathrm{P}<0.001$ ). The first-rank determinants for full migraine without aura were sleep irregularities (OR 1.596; $\mathrm{P}=0.005)$ and periodic vomiting (OR $1.464 ; \mathrm{P}=0.026)$. However, even if not mentioned in ICHD-III beta, the authors determined that motion sickness, abdominal pain or infantile colic attacks in childhood, associated dizziness and osmophobia have important diagnostic value.

CONCLUSIONS: In cases that do not fulfill all of the diagnostic criteria although they are largely consistent with the characteristics of migraine in clinical terms, the authors believe that a history of infantile colic; periodic vomiting (but not periodic vomiting syndrome); recurrent abdominal pain; the presence of motion sickness or vertigo, dizziness or osmophobia accompanying the pain; and comorbid atopic disorder are characteristics that should to be discussed and considered as additional diagnostic criteria (covariates) in the preparation of the final version of ICHD-III.

Key Words: Covariates; Diagnostic criteria; Grey zones; ICHD-III; Migraine without aura

$\overline{\mathrm{M}}$ igraine, a recurring headache disorder manifesting in attacks lasting $4 \mathrm{~h}$ to $72 \mathrm{~h}(1)$ and affecting $2 \%$ to $15 \%$ of the world's population (2) with an estimated one-year prevalence of $16.4 \%$ in Turkey (3), has been associated with significant individual and societal burdens related to disability and productivity loss $(1,4)$.

The most common form of migraine - migraine without aura (MwoA) - is experienced by the large majority of migraineurs (5),
Les zones grises dans le diagnostic de la migraine sans aura chez les adultes, d'après la Classification internationale des céphalées III, version bêta : exploration des covariables d'une éventuelle migraine sans aura

HISTORIQUE : Il peut être utile d'explorer les caractéristiques cliniques et les covariables de la migraine pour diagnostiquer la migraine sans aura. OBJECTIF : Évaluer la valeur du diagnostic de migraine sans aura fondé sur la Classification internationale des céphalées (ICHD)-III, version bêta, explorer les covariables d'éventuelle migraine sans aura par l'analyse des zones grises dans ce secteur et faire des suggestions pour la version définitive de l'ICHD-III. MÉTHODOLOGIE : Au total, 1365 patients (âge moyen [ \pm ÉT] de $38,5 \pm 10,4$ ans, $82,8 \%$ de femmes) ayant un diagnostic de migraine sans aura selon les critères de l'ICHD-III, version bêta, ont participé à la présente étude rétrospective en soins tertiaires. Les patients qui respectaient tous les critères de l'ICHD-III, version bêta, étaient classés comme ayant une migraine sans aura complète, tandis que ceux qui ne respectaient pas un, deux ou au moins trois critères diagnostiques étaient classés comme faisant partie des zones I, II et III, respectivement. Les chercheurs ont déterminé la valeur diagnostique des caractéristiques et covariables cliniques de la migraine.

RÉSULTATS : Une migraine sans aura complète était évidente chez $25,7 \%$ des migraineux. Une crise qui durait plus de quatre à 72 heures (RC 1,$560 ; \mathrm{P}=0,002$ ) avait une qualité pulsatile ( $\mathrm{RC} 4,096 ; \mathrm{P}<0,001$ ), s'accompagnait de nausées ou de vomissements (RC 2,300; $\mathrm{P}<0,001)$ et de photophobie ou de phonophobie $(\mathrm{RC} 4,865 ; \mathrm{P}<0,001)$ était plus susceptible d'être classée dans la zone I. Les premiers déterminants de migraine sans aura complète étaient les irrégularités du sommeil $(\mathrm{RC} 1,596 ; \mathrm{P}=0,005)$ et les vomissements périodiques (RC 1,464; $\mathrm{P}=0,026)$. Cependant, même s'ils ne sont pas soulevés dans l'ICHD-III, version bêta, les auteurs ont déterminé la grande valeur diagnostique du mal des transports, des douleurs abdominales ou des coliques du nourrisson chez les enfants, des étourdissements connexes et de l'osmophobie.

CONCLUSIONS : Dans les cas qui ne respectent pas tous les critères diagnostiques, même s'ils correspondent largement aux caractéristiques cliniques de la migraine, les auteurs pensent que des antécédents de coliques du nourrisson, de vomissements périodiques (mais pas de syndrome de vomissements cycliques), de douleurs abdominales récurrentes, de mal des transports ou de vertige, d'étourdissements ou d'osmophobie accompagnant la douleur et de trouble atopique sont des caractéristiques qu'il faudrait examiner et envisager comme critères diagnostiques supplémentaires (covariables) lors de la préparation de la version finale de l'ICHD-III.

with an incidence ranging from 1.37 to 10.1 per 1000 person-years among men and 2.9 to 18.9 per 1000 person-years among women (6). However, despite being a common disorder frequently encountered in clinical practice, migraine is frequently underdiagnosed and misdiagnosed $(7,8)$.

In 2004, the International Headache Society published the second edition of the International Classification of Headache Disorders

${ }^{1}$ Department of Neurology, Mersin University School of Medicine, Mersin; ${ }^{2}$ Acibadem University School of Medicine, Istanbul, Turkey Correspondence: Aynur Ozge, Department of Neurology, Mersin University School of Medicine, Dumlupinar mah. 1506 Sok. Academy apt, No: 7/3, Mersin, Turkey 33130. Telephone 90-324-331-0301, fax 90-324-331-0201, e-mail aynurozge@gmail.com 


\begin{tabular}{l} 
TABLE 1 \\
International Classification of Headache Disorders-III beta \\
criteria for diagnosing migraine without aura (1.1) (11) \\
\hline A. At least five attacks fulfilling criteria B through $\mathrm{D}$ \\
B. Headache attacks lasting $4 \mathrm{~h}$ to $72 \mathrm{~h}$ (untreated or unsuccessfully treated) \\
C. Headache with at least two of the following characteristics: \\
Unilateral location \\
Pulsating quality \\
Moderate to severe pain \\
Aggravation by or causing avoidance of routine physical activity \\
(eg, walking or climbing stairs) \\
D. During headache at least one of the following: \\
Nausea and/or vomiting \\
Photophobia and phonophobia \\
E. Not attributed to another disorder
\end{tabular}

(ICHD-II) aiming to standardize scattered headache terminology (9). Concerning MwoA, similar to the second edition (ICHD-II), the ICHD-III beta version did not introduce major changes to its predecessor, published in 1998 (ICHD-I) (9-11). ICHD-III beta requires five criteria to diagnose $\mathrm{MwoA}$ in an adult including unilateral pain location with throbbing quality, severe intensity, presence of nausea/ vomiting and/or photophobia/phonophobia, and a duration of $4 \mathrm{~h}$ to $72 \mathrm{~h}$ (11). However, many patients continue to face difficulties in fulfilling the overall criteria in ICHD-III beta to be diagnosed with MwoA, and it appears to be reasonable to classify them in what may be referred to as a 'grey zone'.

Indeed, the criteria included in the original and updated second edition of ICHD were primarily developed to standardize the diagnosis of migraine headache within clinical research trials (12). It is possible that the complexity of the proposed criteria represents a significant barrier to their use as a diagnostic tool by primary care physicians in routine clinical practice (12). As a result of the considerable gap between the practices of researchers and clinicians $(9,13)$, and the adoption of ICHD diagnostic criteria for migraine in a limited manner in clinical practice (12), there are variable data and limited statistical evaluations regarding the characteristics of migraine. Consideration needs to be given to the sensitivity and specificity of the items included in the diagnostic criteria for migraine in the literature (14).

Although the ICHD-III beta version (11) made no significant contribution to MWoA criteria in terms of novelty, following the publication of this version, the ICHD-III beta coordinator, Dr Jes Olesen, has issued a call to clinicians and researchers to submit feedback of their practical experiences and field studies based on their criteria. After this feedback, the category will take its final shape before publishing. In our daily clinical practice, we have encountered several patients who fail to meet the diagnostic criteria, despite being considered to have MwoA in a clinical sense. The present study aimed to clarify some of the issues related to the classification of disease in clinical practice and contribute to the data available on field trials of the ICHD-III beta version.

The present study was designed to retrospectively evaluate the clinical dataset (derived from the Turkish Headache Database) available for patients with MwoA, who were being followed at a tertiary care centre, to determine the diagnostic value of clinical characteristics included in the ICHD-III beta-based diagnostic criteria of MwoA in relation to grey zones in the diagnosis; in addition, we sought to determine potential covariates of a 'possible MwoA'.

\section{Subjects}

\section{METHODS}

From the initial dataset of 3286 patients with migraine, after excluding those with 'possible' diagnosis, known comorbidities and missed clinical variables, a total of 1365 patients diagnosed with MwoA according to the criteria of the ICHD-III beta (11) during their follow-up by the Headache Outpatient Clinic of the Neurology Department of Mersin University School of Medicine (Mersin, Turkey) were included in the present tertiary care-based, retrospective clinical study. Excluded patients were as follows: 619 patients had 'possible MwoA' diagnosis; 423 patients had migraine and tension-type headache, or other primary or secondary causes of headache disorders; and 879 patients had missing clinical variables.

The inclusion criterion was a history of $\geq 5$ migraine attacks. Patients who had medication-overuse headache, pure menstrual migraine or any other associated headache disorder were excluded from the study. In addition, 'advanced' cardiac, respiratory, renal or hepatic diseases; malignancy; major psychiatric disorders or a history of drug/alcohol abuse; and pregnancy before or during the study were considered to be exclusion criteria.

Permission was obtained from the authors' institutional ethics committee for the use of patient data for publication purposes (MEU.0.01.00.06/265, 20.10.2008).

\section{Diagnostic classification of MwoA}

The diagnosis of MwoA was made in accordance with the criteria of the ICHD-III beta (International Headache Society 1.1., International Classification of Diseases, 10th revision, G43.0) (11) (Table 1), based on a history of $\geq 5$ attacks lasting $4 \mathrm{~h}$ to $72 \mathrm{~h}$ (untreated or unsuccessfully treated), showing at least two of the following characteristics: unilateral location, pulsating quality, moderate or severe pain intensity, and aggravation by or causing avoidance of routine physical activity (eg, walking or climbing stairs), accompanied by at least one of the following during headache: nausea and/or vomiting, photophobia and phonophobia, none of which were attributed to another disorder. The patients meeting all of the criteria of the ICHD-III beta - ie, experiencing attacks lasting $4 \mathrm{~h}$ to $72 \mathrm{~h}$ and characterized by a visual analogue scale (VAS) score $\geq 5$ (the midpoint of a zero to 10 VAS), pulsating quality, unilateral location and concomitant nausea and/or vomiting along with photophobia and phonophobia - were classified as having full MwoA.

In addition, cases failing to fulfill only one of the basic diagnostic criteria for migraine, but whose migraine diagnosis was supported by the specialist in clinical terms were classified as zone I; cases failing to fulfill two of the basic diagnostic criteria for migraine, but whose migraine diagnosis was supported by the specialist in clinical terms were classified as zone II; and cases failing to fulfill three of the basic diagnostic criteria for migraine, but whose migraine diagnosis was supported by the specialist in clinical terms were classified as zone III.

\section{Assessments}

The diagnostic value of the clinical characteristics included among the ICHD-II-based diagnostic criteria of MwoA was evaluated with respect to the diagnostic classification of patients as full MwoA, and the grey zones I to III.

The role of sex and covariates in the diagnosis of full MwoA, zone 1 , zone II and zone III classifications were evaluated via univariate analysis. Patients in each diagnostic classification were compared in terms of sex distribution and the presence of covariates, including motion sickness, periodic vomiting, abdominal pain, allergy, infantile colic, premature birth, emotional distress, physical activity, factors related to the menstrual cycle, seasonal factors, fasting, dizziness, sleep irregularities, vertigo, osmophobia and allodynia, as well as the duration of pain.

The significance of the covariates in each diagnostic classification was ranked via multiple logistic regression analysis for the variables determined to be associated with a significance of $\leq 0.20$ in the univariate analysis.

\section{Statistical analysis}

Regression analysis was performed with the variables determined to be associated with a significance of $\leq 0.20$ in the univariate analysis. Predictors with a possible influence on a dependent variable were added as covariates. Data were expressed as mean $\pm \mathrm{SD}$, percent and 
TABLE 2

Diagnostic value of clinical characteristics included in International Classification of Headache Disorders-III beta-based diagnostic criteria

\begin{tabular}{|c|c|c|c|c|c|c|c|c|c|}
\hline \multirow[b]{2}{*}{ Diagnostic criteria* } & \multicolumn{3}{|c|}{ Zone I ( $n=546)$} & \multicolumn{3}{|c|}{ Zone II (n=327) } & \multicolumn{3}{|c|}{ Zone III (n=141) } \\
\hline & $\mathrm{n}(\%)$ & OR $(95 \% \mathrm{Cl})$ & $\mathbf{P}$ & n (\%) & OR $(95 \% \mathrm{Cl})$ & $\mathbf{P}$ & n (\%) & OR $(95 \% \mathrm{Cl})$ & $\mathbf{P}$ \\
\hline Lasting $4 \mathrm{~h}$ to $72 \mathrm{~h}$ & $455(83.3)$ & $1.560(1.180-2.062)$ & 0.002 & $212(64.8)$ & $0.355(0.268-0.471)$ & $<0.001$ & $41(41.0)$ & $0.150(0.098-0.229)$ & $<0.001$ \\
\hline Severity of $\geq 5^{\dagger}$ & $544(99.6)$ & $3.565(0.778-16.335)$ & 0.138 & $321(98.2)$ & $0.326(0.104-1.016)$ & 0.084 & $91(95.8)$ & $0.150(0.044-0.506)$ & 0.008 \\
\hline Unilateral location & $168(30.8)$ & $0.431(0.343-0.541)$ & $<0.001$ & $40(12.2)$ & $0.127(0.089-0.180)$ & $<0.001$ & $25(17.7)$ & $0.256(0.164-0.401)$ & $<0.001$ \\
\hline $\begin{array}{l}\text { Nausea and/or } \\
\text { vomiting }\end{array}$ & $506(92.7)$ & $2.300(1.583-3.342)$ & $<0.001$ & $257(78.6)$ & $0.374(0.267-0.524)$ & $<0.001$ & $85(60.3)$ & $0.150(0.101-0.221)$ & $<0.001$ \\
\hline
\end{tabular}

phonophobia

Bolded values indicate statistical significance. *The patients meeting all of the criteria of the International Classification of Headache Disorders-III beta ( $n=351)$ were classified as having full migraine without aura, while if they failed to meet one, two or $\geq 3$ of the criteria for the diagnostic gold standard they were classified as being in the grey diagnostic zones of zone I, zone II or zone III, respectively; †Visual analogue scale score of pain severity

\section{TABLE 3}

Diagnostic value of sex and medical history in the diagnosis full migraine without aura (MWoA) and grey zones I through III

\begin{tabular}{|c|c|c|c|c|c|}
\hline & Full MwoA $\left(n=351^{*}\right)$ & Zone I $\left(n=546^{*}\right)$ & Zone II $\left(n=327^{\star}\right)$ & Zone III $\left(n=141^{*}\right)$ & $\mathbf{P}$ \\
\hline \multicolumn{6}{|l|}{ Sex } \\
\hline Male & $35(10)$ & $61(11.3)$ & $45(13.9)$ & $21(15.8)$ & 0.217 \\
\hline Female & $314(90)$ & $480(88.7)$ & $279(86.1)$ & $112(84.2)$ & \\
\hline \multicolumn{6}{|c|}{ Premature birth } \\
\hline Absent & $57(90.5)$ & $106(90.6)$ & $73(93.6)$ & $25(96.2)$ & 0.713 \\
\hline Present & $6(9.5)$ & $11(9.4)$ & $5(6.4)$ & $1(3.8)$ & \\
\hline \multicolumn{6}{|c|}{ Infantile colic } \\
\hline Absent & $59(93.7)$ & $102(87.2)$ & $75(96.2)$ & $26(100)$ & 0.041 \\
\hline Present & $4(6.3)$ & $15(12.8)$ & $3(3.8)$ & $0(0.0)$ & \\
\hline \multicolumn{6}{|c|}{ Periodic vomiting } \\
\hline Absent & $262(75.9)$ & $428(80.5)$ & $263(81.2)$ & $121(87.1)$ & 0.041 \\
\hline Present & $83(24.1)$ & 104 (19.5) & $61(18.8)$ & $18(12.9)$ & \\
\hline \multicolumn{6}{|c|}{ Abdominal pain } \\
\hline Absent & $230(65.5)$ & 387 (70.9) & $254(77.7)$ & $127(86.5)$ & $<0.001$ \\
\hline Present & 121 (34.5) & $159(29.1)$ & $73(22.3)$ & $19(13.5)$ & \\
\hline \multicolumn{6}{|l|}{ Allergy } \\
\hline Absent & $194(55.3)$ & 292 (53.5) & $193(59.0)$ & $82(58.2)$ & 0.404 \\
\hline Present & $157(44.7)$ & $254(46.5)$ & $134(41.0)$ & $59(41.8)$ & \\
\hline
\end{tabular}

Data presented as $n(\%)$ unless otherwise indicated. Bolded values indicate statistical significance. *The sum of patient numbers is lower for some variables because of missing data

median. Statistical analysis was conducted using SPSS version 13.0 (IBM Corporation, USA). The predictive role of the clinical characteristics of migraine considered among the diagnostic criteria of MwoA, together with the role of sex and covariates in the diagnosis of full MwoA, zone 1, zone II and zone III, was evaluated via univariate analysis. The significance of covariates was ranked via regression analysis and $\mathrm{OR}, 95 \% \mathrm{CI}$ where appropriate. $\mathrm{P}<0.05$ was considered to be statistically significant.

\section{RESULTS}

The diagnostic values of the clinical characteristics are included in the ICHD-III beta based diagnostic criteria. Of 1365 patients (mean [ $\pm \mathrm{SD}$ ] age $38.5 \pm 10.4$ years [range 18 to 75 years], $88.2 \%$ women), the mean headache duration was $7.01 \pm 6.56 \mathrm{~h}$, frequency was $8.83 \pm 8.67$ days per month and severity was $7.09 \pm 1.93$ according to VAS. When the history of the patients was evaluated, periodic vomiting was observed in $22.7 \%$ of the patients, recurrent abdominal pain in $27.2 \%$, motion sickness in $58.6 \%$ and atopic disorders in $53.9 \%$. When the triggering factors were observed, emotional stress was detected in $91.3 \%$ of patients, and factors related to the menstrual cycle in $64.2 \%$. A total of $77.3 \%$ of the patients stated that their pain was exacerbated by routine physical activity. Among the pain-related findings, nausea was detected in $98.3 \%$ of patients, vomiting in $70.6 \%$, phonophobia in $91.9 \%$ and photophobia in $83.5 \%$.
Only 351 (25.7\%) patients were classified as having full MwoA. However, 546 (40.0\%) patients were classified as zone I, 327 (24.0\%) patients as zone II and $141(10.3 \%)$ as zone III, according to the criteria mentioned above.

\section{MWoA}

A total of 351 patients fulfilled all the MwoA diagnostic criteria; this was confirmed using the ICHD-III beta. Ninety percent of these patients were female (Table 2). These patients constituted the largest group in terms of a history of periodic vomiting $(24.1 \%)$ and of abdominal pain that was not associated with any other cause $(34.5 \%)$ (Table 3). In this group, the most common triggering factor was emotional distress (98.0\%) (Table 4). Motion sickness (57.8\%), osmophobia $(76.9 \%)$ and sleep irregularities $(76.4 \%)$, which are not included among the factors related to migraine in the diagnostic criteria, were found to be significantly associated with MWoA (Table 5). Among the variables studied, in terms of covariate factors, sleep irregularities in men (OR 1.596) and periodic vomiting in women (OR 1.464) were the 'most important' (first degree) variables $(\mathrm{P}<0.05)$. Osmophobia (OR 1.348) and motion sickness (OR 1.237) were second-degree variables; these symptoms were more distinct in men. Third-degree variables in full MwoA included emotional distress (OR 1.263), abdominal pain (OR 1.083), allodynia (OR 0.647) and dizziness (OR 1.045); these were also more commonly observed in male 
TABLE 4

Diagnostic value of some triggers in the diagnosis of full migraine without aura (MWoA) and the grey zones I to III

\begin{tabular}{|c|c|c|c|c|c|}
\hline & Full MwoA $\left(n=351^{*}\right)$ & Zone I $(n=546 *)$ & Zone II $\left(n=327^{*}\right)$ & Zone III ( $\left.\mathrm{n}=141^{*}\right)$ & $\mathbf{P}$ \\
\hline \multicolumn{6}{|c|}{ Emotional distress } \\
\hline Absent & $7(2.0)$ & $13(2.4)$ & $23(7.1)$ & $30(21.4)$ & $<0.001$ \\
\hline Present & $344(98.0)$ & $531(97.6)$ & 301 (92.9) & $110(78.6)$ & \\
\hline Absent & $67(19.1)$ & $94(17.3)$ & $55(17)$ & $23(16.4)$ & 0.851 \\
\hline Present & $284(80.9)$ & $450(82.7)$ & $269(83)$ & 117 (83.6) & \\
\hline \multicolumn{6}{|c|}{ Menstrual factors } \\
\hline Present & $167(53.2)$ & $275(58.1)$ & $135(51.1)$ & $47(44.8)$ & \\
\hline \multicolumn{6}{|c|}{ Seasonal factors } \\
\hline Absent & $184(53.5)$ & $306(57.1)$ & $178(56.2)$ & $81(58.7)$ & 0.672 \\
\hline Present & $160(46.5)$ & $230(42.9)$ & $139(43.8)$ & $57(41.3)$ & \\
\hline \multicolumn{6}{|l|}{ Fasting } \\
\hline Absent & $98(27.9)$ & $153(28.1)$ & $89(27.5)$ & $46(23.9)$ & 0.667 \\
\hline
\end{tabular}

Data presented as $n$ (\%) unless otherwise indicated. *The sum of patient numbers was lower for some variables because of missing data. Bolded values indicate statistical significance

TABLE 5

Diagnostic value of some associated factors for the diagnosis of full migraine without aura (MWoA) and the grey zones I to III

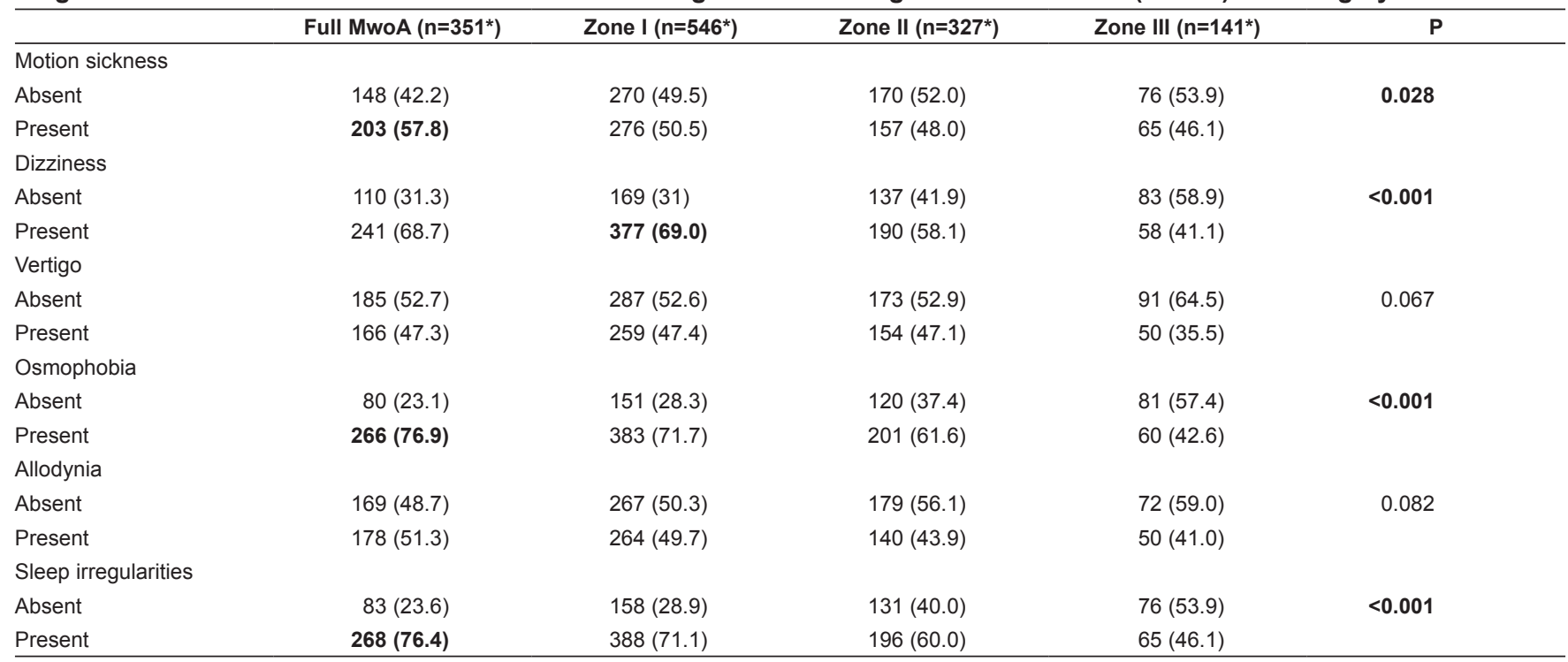

Data presented as $n(\%)$ unless otherwise indicated. ${ }^{*}$ The sum of patient numbers was lower for some variables because of missing data. Bolded values indicate statistical significance

patients compared with female patients. Allergy, infantile colic, heavy physical activity, vertigo, menstrual factors, seasonal factors and fasting had a negligible effect on the state of full MwoA (Table 6).

\section{Zone I}

There were 546 patients $(40.0 \%)$ who failed to fulfill only one of the standard diagnostic criteria (zone I); they formed the largest group of all the groups studied. In this group, it was notable that at least one of the characteristics, except for the pain level, was missing in at least one of the patients at varying rates (30\% to $90.1 \%$ ). The least commonly observed characteristic was unilateral localization of the pain (30.8\%; OR 0.431; $\mathrm{P}<0.001)$ (Table 2). A history of infantile colic was significantly higher in zone I patients $(12.8 \% ; \mathrm{P}=0.041)$ (Table 3$)$. The prominent triggering factor in the group was menstruation (58.1\%; $\mathrm{P}=0.050$ ) (Table 4). Among the factors associated with migraine, dizziness $(69.0 \% ; \mathrm{P}<0.001)$ became increasingly prevalent (Table 5). When observed in terms of covariates, the most effective variable for women in zone 1 was a history of infantile colic (OR 5.111). The second most effective variable of the group as a whole was menstrual triggering (OR 1.669), while third among the effective variables were a history of pain-associated dizziness (OR 1.299) and accompanying sleep irregularity (OR 0.839). A history of accompanying atopic disorder (OR 0.931) and osmophobia (OR 1.027) were the fourth most effective variables. The effect of other covariates in the relevant patient group was negligible (Table 6).

\section{Zone II}

There were 327 (24.0\%) patients who did not meet two of the standard diagnostic criteria (zone II); all variables, except for the pain level and accompanying photophobia and/or phonophobia, showed a diagnostic effect (Table 2). In this group's history, no significant variable was detected (Table 3), nor were any meaningful risk factors and accompanying symptoms detected (Tables 4 and 5). When assessed in terms of covariate factors, the most effective variable for these patients was the presence of accompanying sleep irregularities in women (OR 0.732). The second most effective variables for patients of both sexes were a history of abdominal pain (OR 0.742), and accompanying dizziness (OR 0.864) or osmophobia (OR 0.863). The third most 
TABLE 6

Rank of significance among covariates ( $\mathrm{P}$ value in univariate analysis $[\mathrm{Pu}] \leq 0.20$ ) as determinant in the diagnosis of full migraine without aura (MWoA) and the grey zones

\begin{tabular}{|c|c|c|c|c|c|}
\hline & \multicolumn{4}{|c|}{$\mathrm{Pu} \leq 0.20$} & \multirow{2}{*}{$\begin{array}{l}\mathrm{Pu}>0.20 \\
\text { Fifth degree }\end{array}$} \\
\hline & $\begin{array}{l}\text { First degree } \\
\text { Pm } \leq 0.05\end{array}$ & $\begin{array}{l}\text { Second degree } \\
\mathrm{Pm} 0.05 \text { to } \leq 0.50\end{array}$ & $\begin{array}{c}\text { Third degree } \\
\text { Pm } 0.50 \text { to } \leq 0.80\end{array}$ & $\begin{array}{l}\text { Fourth degree } \\
\qquad \mathrm{Pm}>0.80\end{array}$ & \\
\hline Full Mwo & $\begin{array}{l}\text { Sleep irregularities (OR 1.596)* } \\
\text { Periodic vomiting (OR 1.464) }\end{array}$ & $\begin{array}{l}\text { Osmophobia (OR 1.348) } \\
\text { Motion sickness (OR 1.237) }\end{array}$ & $\begin{array}{l}\text { Emotional distress (OR 1.263) } \\
\text { Abdominal pain (OR 1.083) } \\
\text { Allodynia (OR 0.647) } \\
\text { Dizziness (OR 1.045) }\end{array}$ & & $\begin{array}{l}\text { Atopic disorders; } \\
\text { infantile colic; physical } \\
\text { activity; vertigo; } \\
\text { menstrual factors; } \\
\text { seasonal factors; } \\
\text { fasting }\end{array}$ \\
\hline Zone I & Infantile colic (OR 5.111) ${ }^{\dagger}$ & Menstrual factors (OR 1.669) & $\begin{array}{l}\text { Dizziness (OR 1.299) } \\
\text { Sleep irregularities (OR 0.839) }\end{array}$ & $\begin{array}{l}\text { Atopic disorders (OR 0.931) } \\
\text { Osmophobia (OR 1.027) }\end{array}$ & $\begin{array}{l}\text { Motion sickness; } \\
\text { periodic vomiting; } \\
\text { abdominal pain; } \\
\text { physical activity; } \\
\text { vertigo; seasonal } \\
\text { factors; fasting; } \\
\text { allodynia }\end{array}$ \\
\hline Zone II & Sleep irregularities $(\mathrm{OR} 0.732)^{\dagger}$ & $\begin{array}{l}\text { Abdominal pain (OR 0.742) } \\
\text { Dizziness (OR 0.864) } \\
\text { Osmophobia (OR 0.863) }\end{array}$ & $\begin{array}{l}\text { Atopic disorders (OR 0.918) } \\
\text { Motion sickness (OR 1.106) }\end{array}$ & Allodynia (OR 0.983) & $\begin{array}{l}\text { Periodic vomiting; } \\
\text { infantile colic; physical } \\
\text { activity; vertigo; } \\
\text { menstrual factors; } \\
\text { seasonal factors; } \\
\text { fasting }\end{array}$ \\
\hline Zone III & $\begin{array}{l}\text { Osmophobia (OR 0.385)* } \\
\text { Sleep irregularities (OR 0.642) }{ }^{\dagger}\end{array}$ & $\begin{array}{l}\text { Periodic vomiting (OR 0.592) } \\
\text { Abdominal pain (OR 0.584) } \\
\text { Dizziness (OR 0.793) } \\
\text { Allodynia (OR 1.290) }\end{array}$ & $\begin{array}{l}\text { Motion sickness (OR 1.188) } \\
\text { Vertigo (OR 1.137) }\end{array}$ & Menstrual factors (OR 0.995) & $\begin{array}{l}\text { Atopic disorders; } \\
\text { infantile colic; physical } \\
\text { activity; seasonal } \\
\text { factors; fasting }\end{array}$ \\
\hline
\end{tabular}

${ }^{*}$ More commonly observed in male patients; ${ }^{\dagger}$ More commonly observed in female patients. Pm $P$ value in multivariate analysis

effective variables were accompanying atopic disorders (OR 0.918) or a history of motion sickness (OR 1.106). The accompanying allodynia (OR 0.983) was the least effective variable, while the effect of other variables was negligible (Table 6).

\section{Zone III}

There were 141 patients (10.3\%) who did not fulfill $\geq 3$ of the standard diagnosis criteria although they were diagnosed as MwoA in clinical terms. In this group, the diagnostic criteria were statistically significant (Table 2). However, no single triggering factor or accompanying symptom in the patients' history was prominent (Tables 3 to 5). When the diagnostic values of the covariates of this group were observed, the most meaningful clinical characteristics were accompanying osmophobia (OR 0.385) for men and sleep irregularities (OR 0.642) for women. The second most effective variables, regardless of sex, were a history of periodic vomiting (OR 0.592) or recurrent abdominal pain (OR 0.584), and associated dizziness (OR 0.793) or allodynia (OR 1.290). While a history of accompanying motion sickness (OR 1.188) or vertigo (OR 1.137) was the third most effective feature, menstrual triggering (OR 0.995) was the fourth most effective. The effect of the other covariates was negligible (Table 6).

When all the variables were evaluated together, the diagnostic order of covariates for full MwoA diagnosis was as follows: associated sleep dysregulation, a history of periodic vomiting, associated osmophobia, motion sickness, triggered emotional stress, recurrent abdominal pain and a history of atopic disorders (Figure 1).

\section{DISCUSSION}

The present study involved the retrospective evaluation of patients diagnosed with MwoA by a headache specialist using a semistructured headache database system. In terms of the diagnostic value of the clinical characteristics included among the ICHD-III beta-based diagnostic criteria, it was revealed that only $25.7 \%$ of patients were categorized as full MwoA, while $74.3 \%$ failed to fulfill ICHD/ICHD-III

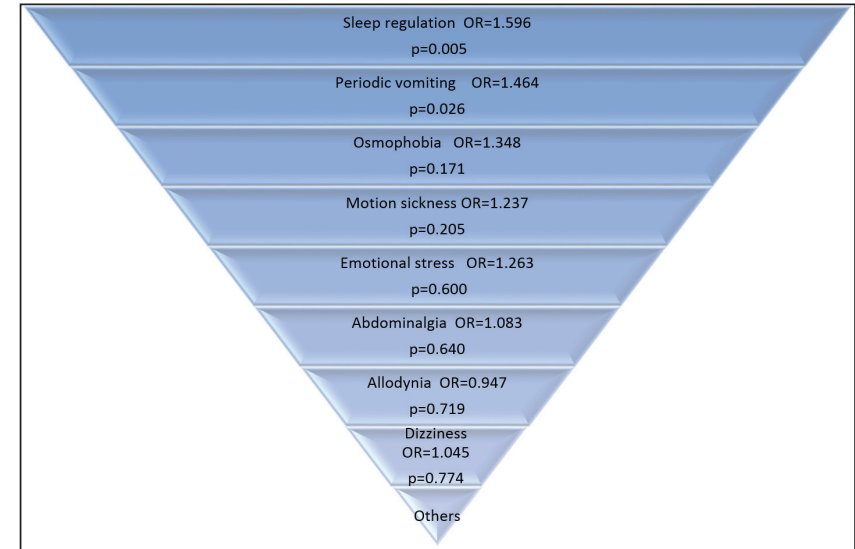

Figure 1) Ranking of the covariates for the diagnosis of full migraine without aura according to statistical significance

beta-based diagnostic criteria and were, thus, categorized in three grey zones: I (40.0\%), II (24.0\%) and III (10.3\%). The severity of the headache and presence of photophobia and/or phonophobia were the best diagnostic items evident in the greatest number of patients, regardless of their classification, whereas unilateral location and pulsating quality were significantly less common in the grey zones.

When a patient meets all criteria except one, migraine is classified as migrainous disorder in ICHD I (1988) (10) and probable migraine in ICHD II (2004) (9). A study involving a critical analysis of ICHD I (1988) and ICHD II (2004) for migraine in children and adolescents reported that $57 \%$ of the cases were diagnosed as migrainous disorder and $30 \%$ as probable migraine (15).

The rationale for performing the present study was that in daily practice, we, as physicians abiding by the ICHD classification, encounter many patients who do not fulfill all the criteria, but for whom 
inclusion in the class of 'possible' sufferers is not the solution. As also revealed by the present data set, the full MwoA group constituted only one of four $(25.7 \%)$ cases diagnosed with MwoA by the clinician, and this was merely the 'tip of the iceberg'. We aimed to identify the covariates determining the remaining cases and, perhaps, make some contribution to the committee, in particular at a time when we are discussing the final version of ICHD-III and its class criteria.

The full MwoA group revealed the importance of a history of recurrent abdominal pain and periodic vomiting, in addition to other previously known characteristics of migraine. Motion sickness, osmophobia and associated sleep irregularities, which are also observed in a high proportion of these patients, do not appear among the diagnostic criteria in the ICHD-III beta version, but are covariates that are should be taken into consideration. Of these characteristics, some (sleep irregularities and periodic vomiting) were more important in women, while others (osmophobia and motion sickness) applied more to men. To the best of our knowledge, the present study was the first to analyze the diagnostic criteria of headache in the context of group covariate analysis, particularly using a large database. In the literature, excessive daytime sleepiness, difficulty initiating and maintaining sleep, early morning awakening and daytime fatigue (16) were reported as the most commonly encountered sleep disturbances among migraineurs, with negative impact on their quality of life and a higher rate of morbidity (17). Given that patients with MwoA have a much higher prevalence of sleep abnormalities than control patients, possibly due to multiple contributory factors (17), our finding that sleep irregularities are first-rank determinants of the migraineurs with full MwoA diagnosis is notable. However, we could not identify evidence of sleep irregularities having sex-related diagnostic significance in the literature.

Osmophobia characterized by hyperosmia combined with avoidant behaviours and functional impairment is a rare, specific phobic disorder, although commonly observed in patients with migraine (18). In correlation to its identification as a second-degree determinant of full MwoA in our study population, osmophobia has been considered to be an important clinical feature of the headache pattern closely associated with migraine, not only because it is significantly more frequent in migraineurs but also because it has an important prognostic value (19).

Similarly, two important diagnostic features that should be discussed are previous periodic vomiting and recurrent abdominal pain. Patients with cyclic vomiting were reported to have a higher incidence of migraine than the general population ( $22 \%$ and $5 \%$, respectively) $(20,21)$, while a higher prevalence of colic $(29 \%$ versus $11 \%)$ was reported in the infants of migraineur mothers (22). However, while these characteristics are explained in the classification as supportive characteristics, no satisfying explanation on their diagnostic importance has been offered, except for periodical symptoms. In our analyses, these covariates, coming to the forefront particularly among women, deserve to be rediscussed as diagnostic characteristics.

Analysis of cases in zone I, the largest group, revealed that the diagnosis of $40 \%$ of the patients may change if the diagnostic criteria are reviewed. In this group, we observed that a history of infantile colic with associated dizziness and a medical history of atopic disorder were present to a marked degree, and that menstrual triggering was also important in women. The predictive role of both cyclic vomiting (23)

\section{REFERENCES}

1. Diener HC, Dodick DW, Goadsby PJ, et al. Chronic migraine classification, characteristics and treatment. Nat Rev Neurol 2012;8:167-172.

2. The World Health Report 2001. Mental Health: New Understanding, New Hope. Geneva: WHO, 2001.

3. Zarifoglu M, Karli N, Taskapilioglu O. Can ID migraine be used as a screening test for adolescent migraine? Cephalalgia 2007;28:65-71.

4. Olesen J, Gustavsson A, Svensson M, et al. The economic cost of brain disorders in Europe. Eur J Neurol 2012;19:155-62. and infantile colic $(22,24)$ in MwoA diagnosis in our study population supports the fact that they have commonly been considered to be precursors to migraine. Symptoms of dizziness or vertigo were reported in $54 \%$ and motion sickness, the most common vestibular symptom, in more than one-half of patients with migraine, with increased susceptibility to motion sickness among migraineurs (25). At the same time, the diagnostic importance of the migraine-atopy association and accompanying dizziness/vertigo or motion sickness was emphasized in our previous studies $(26,27)$. The analysis of the present dataset once again verifies the previous clinical study data.

Pain level was an important determinant in zone II. Covariates matched up with the previous zones. Sleep irregularities were observed to be an important covariate, particularly among women, supporting the increasing interest in recent years in sleep irregularities accompanying migraine patients $(8,16,19)$. We believe that more research should be conducted on the subject.

No different diagnostic characteristic stood out in zone III; ie, this was the zone closest to the spectrum's 'possible' end. We wish to emphasize here that vertigo accompanying headache attacks, although not having a coefficient as highly significant as dizziness, is a relatively rarely discussed characteristic in the literature, notwithstanding its appearance in our previous clinical studies (27). In this group, allodynia was found to be the second most important variable. Allodynia is defined as the perception of pain in response to normal activities, such as shaving, showering or wearing jewelry, and is reported in $63 \%$ to $79 \%$ of migraineurs (28), while severe pain was associated with a higher number of triggers in migraineurs (29). Given the likely role of allodynia in migraine transformation, lowering the migraine-attack threshold and, thus, facilitating an increase in headache frequency (30), it appears notable that allodynia was the second most important determinant that was positively correlated with zone III classification, which includes patients lacking $\geq 3$ of the diagnostic criteria for MwoA.

Our study aimed to contribute to new efforts to determine classification, from a unique point of view and by including the unique analysis of a large patient group diagnosed by a headache specialist at a tertiary centre. Moreover, while the performance of retrospective analysis in the dataset is a restriction in principle, it may be useful to recall that all the diagnoses were made after the fulfillment of basic requirements such as clinical inspection and medical examination.

\section{CONCLUSION}

In cases that do not fulfill all the diagnostic criteria although they largely support the diagnosis of migraine in clinical terms, we believe that additional diagnostic characteristics (covariates), such as infantile colic, periodic vomiting, recurrent abdominal pain, the presence of motion sickness or vertigo, dizziness or osmophobia accompanying the pain, and a history of comorbid atopic disorder, are characteristics that merit discussion and consideration as additional diagnostic criteria (covariates) in preparing the final version of the ICHD-III.

ACKNOWLEDGMENTS: The Turkish Headache Database system is an official system of the Turkish Headache Study Group. It has been compiled by Aynur Ozge MD since 2004 and is partially supported by the Turkish Neurology Society. All the authors contributed equally to the present study.

5. Launer LJ, Terwindt GM, Ferrari MD. The prevalence and characteristics of migraine in a population-based cohort. Neurology 1999;53:537-42.

6. Stewart WF, Lipton RB, Celentano DD, et al. Prevalence of migraine headache in the United States. Relation to age, income, race, and other sociodemographic factors. JAMA 1992;267:64-9.

7. Stang PE, Von Korff M. The diagnosis of headache in primary care: Factors in the agreement of clinical and standardized diagnoses. Headache 1994;34:138-42. 
8. Tepper SJ, Dahlöf CG, Dowson A, et al. Prevalence and diagnosis of migraine in patients consulting their physician with a complaint of headache: Data from the Landmark Study. Headache 2004:44:856-64.

9. Headache Classification Subcommittee of the International Headache Society. The international classification of headache disorders. 2nd edition. Cephalalgia 2004:24 (Suppl 1):1-160.

10. Headache Classification Committee of the International Headache Society: Classification and diagnostic criteria for headache disorders, cranial neuralgias and facial pain. Cephalalgia 1988;8(Suppl 7):1-96.

11. The International Classification of Headache Disorders, 3rd edition (beta version). Headache Classification Committee of the International Headache Society (IHS). Cephalalgia 2013;33:629-808.

12. Martin VT, Penzien DB, Houle TT, et al. The predictive value of abbreviated migraine diagnostic criteria. Headache 2005;45:1102-12.

13. Ghandehari K, Ashrafzadeh F, Mood ZI, et al. Development and validation of the Asian Migraine Criteria (AMC). J Clin Neurosci 2012;19:224-8

14. Pacheva I, Milanov I, Ivanov I, et al. Evaluation of diagnostic and prognostic value of clinical characteristics of migraine and tension type headache included in the diagnostic criteria for children and adolescents in International Classification of Headache Disorders second edition. Int J Clin Pract 2012;66:1168-77.

15. Lima MM, Padula NA, Santos LC, et al. Critical analysis of the International Classification of Headache Disorders diagnostic criteria (ICHD I-1988) and (ICHD II-2004), for migraine in children and adolescents. Cephalalgia 2005;25:1042-7.

16. Lateef T, Swanson S, Cui L, et al. Headaches and sleep problems among adults in the United States: Findings from the National Co-morbidity Survey-Replication study. Cephalalgia 2011;31:648-53.

17. Karthik N, Kulkarni GB, Taly AB, et al. Sleep disturbances in 'migraine without aura' - a questionnaire based study. J Neurol Sci 2012;321:73-6.
18. Kuo YH, Chang Y, Chen HC, et al. Sertraline alleviated osmophobia caused by partial hypopituitarism with isolated ACTH deficiency. Gen Hosp Psychiatry 2012 August 15 [Epub ahead of print].

19. De Carlo D, Dal Zotto L, Perissinotto E, et al. Osmophobia in migraine classification: A multicentre study in juvenile patients. Cephalalgia 2010;30:1486-94.

20. Cuvellier JC and Lépine A. Childhood periodic syndromes. Pediatr Neurol 2010;42:1-11.

21. Oki J, Miyamoto A, Takahashi S, et al. Cyclic vomiting and elevation of creatine kinase associated with bitemporal hypoperfusion and EEG abnormalities: A migraine equivalent? Brain Dev 1998;20:186-9.

22. Gelfand AA, Thomas KC, Goadsby PJ. Before the headache: Infant colic as an early life expression of migraine. Neurology 2012;79:1392-6.

23. Lin YP, Ni YH, Weng WC, et al. Cyclic vomiting syndrome and migraine in children. J Formos Med Assoc 2011;110:382-7.

24. Jan MM, Al-Buhairi AR. Is infantile colic a migraine-related phenomenon? Clin Pediatr (Phila) 2001;40:295-7.

25. Furman JM, Marcus DA. Migraine and motion sensitivity. Continuum (Minneap Minn) 2012;18(5 Neuro-otology):1102-17.

26. Ozge A, Ozge C, Oztürk C, et al. The relationship between migraine and atopic disorders - the contribution of pulmonary function tests and immunological screening. Cephalalgia 2006;26:172-9.

27. Akdal G, Ozge A, Ergör G. The prevalence of vestibular symptoms in migraine or tension-type headache. J Vestib Res 2013;23:101-6.

28. Abel H. Migraine headaches: Diagnosis and management. Optometry 2009;80:138-48.

29. Baldacci F, Vedovello M, Ulivi M, et al. Triggers in allodynic and non-allodynic migraineurs. A clinic setting study. Headache 2013;53:152-60.

30. Lipton RB, Bigal ME, Ashina S, et al. American Migraine Prevalence Prevention Advisory Group. Cutaneous allodynia in the migraine population. Ann Neurol 2008;63:148-58. 


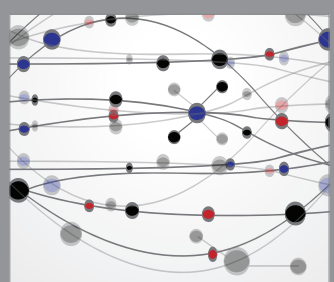

The Scientific World Journal
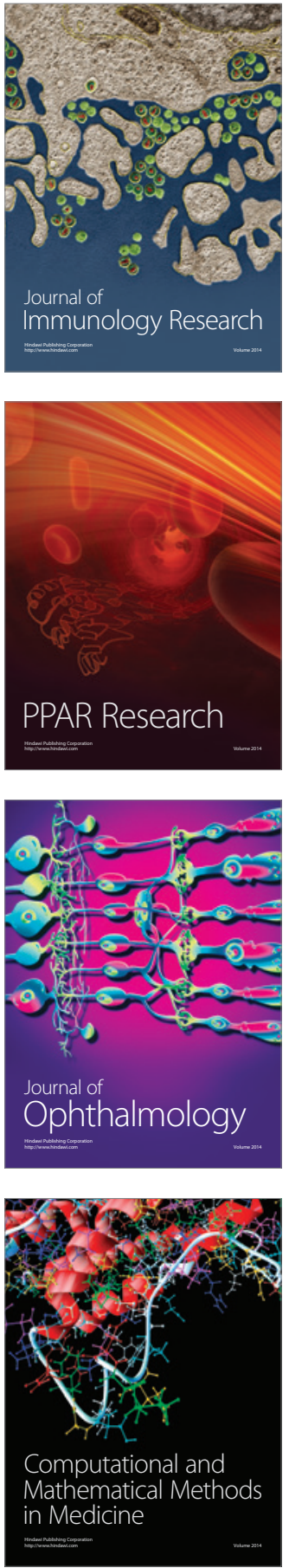

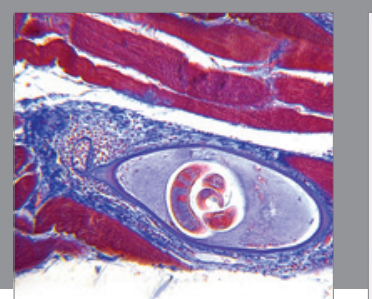

Gastroenterology Research and Practice

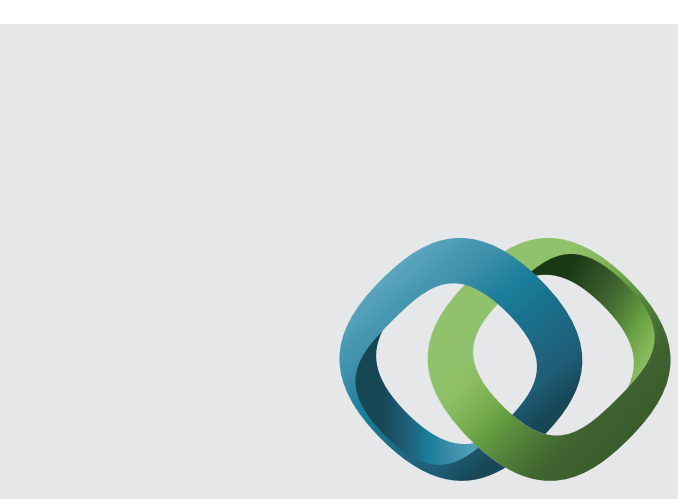

\section{Hindawi}

Submit your manuscripts at

http://www.hindawi.com
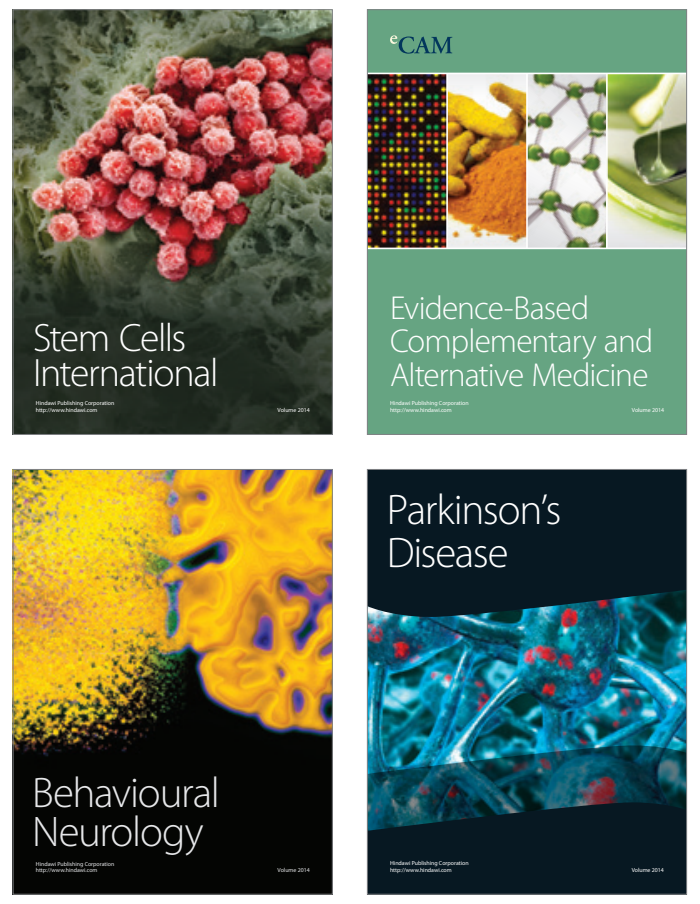
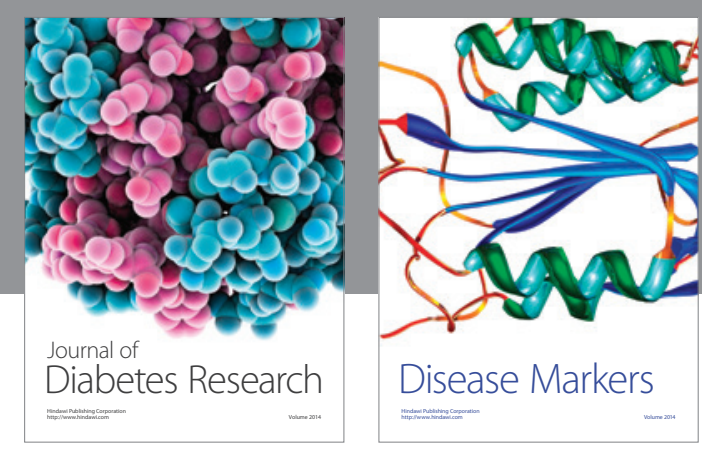

Disease Markers
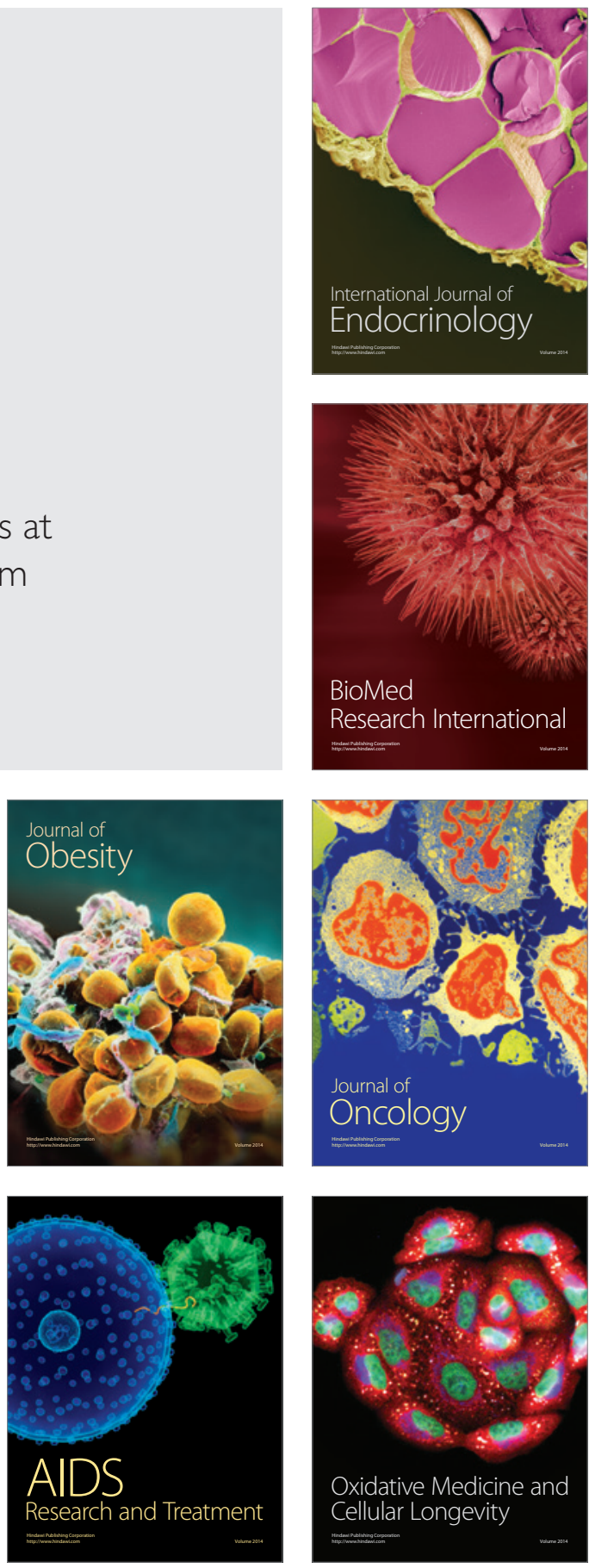